\title{
Public Health Administration
}

National Cancer Institute

\section{Source}

National Cancer Institute. Public Health Administration. NCI Thesaurus. Code C15309.

A health profession that focusses on community-wide disease prevention and health promotion. Public health administrators run the organizations that promote health and disseminate information about health. 